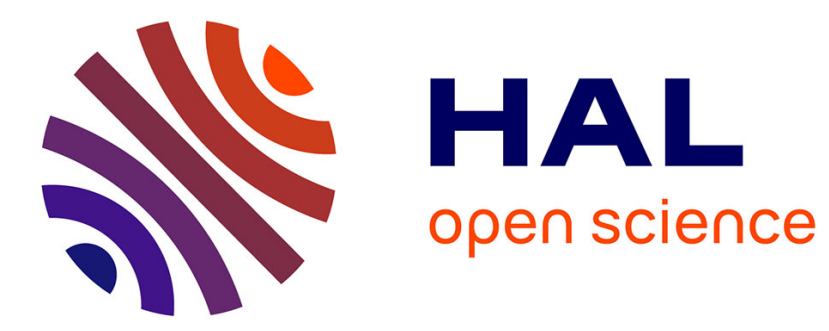

\title{
Validation of a Model for Multiple Agglomeration
}

Ana Cameirão, Fabienne Espitalier, René David, Loïc Rouleau

\section{To cite this version:}

Ana Cameirão, Fabienne Espitalier, René David, Loïc Rouleau. Validation of a Model for Multiple Agglomeration. Chemical Engineering and Technology, 2006, 29 (2), pp.171-174. 10.1002/ceat.200500367 . emse-00612137

\section{HAL Id: emse-00612137 https://hal-emse.ccsd.cnrs.fr/emse-00612137}

Submitted on 5 Sep 2018

HAL is a multi-disciplinary open access archive for the deposit and dissemination of scientific research documents, whether they are published or not. The documents may come from teaching and research institutions in France or abroad, or from public or private research centers.
L'archive ouverte pluridisciplinaire HAL, est destinée au dépôt et à la diffusion de documents scientifiques de niveau recherche, publiés ou non, émanant des établissements d'enseignement et de recherche français ou étrangers, des laboratoires publics ou privés. 


\title{
Validation of a Model for Multiple Agglomeration
}

\author{
By Ana Cameirão, Fabienne Espitalier*, René David, and Lö̈c Rouleau
}

A two-step agglomeration model is developed for the crystallization of a zeolite. It accounts for the crystallization of crystallites from the amorphous phase and the subsequent growth and agglomeration processes. The model explains the morphology of agglomerates with multiple structures, which were obtained. When porosity of the secondary agglomerates is introduced in the model, the agreement with experimental data is largely improved.

\section{Introduction}

Several crystallization products exhibit multiple levels of agglomeration: basic crystallites are embedded in primary agglomerates which, in turn, are reagglomerated in secondary agglomerates. The structure properties like porosities or sizes of the different levels of these particles influence their properties of use like catalytic performances or flowability.

A previous work [1] dealt with the hydrothermal autoclave crystallization of a zeolite from a gel containing amorphous particles. After pouring the reactants into the autoclave vessel, heating up to $150-200^{\circ} \mathrm{C}$ was started. Then, the transformation into crystallites and the consecutive growth and agglomeration of these crystallites required about 72 hours to be completed. Chemical composition, stirring speed, temperature and ripening of the gel were varied. Final crystal size distributions, the desupersaturation profile and the crystallinity index against time were monitored.

\section{Generation of Crystallites}

Crystallites were supposed to be generated from amorphous particles with size $\mathrm{L}_{0}$ and volume $\mathrm{v}_{0}$ from surface contamination by a shrinking core model. This process starts at $t_{0}$. The conversion into a crystallite is completed within $t_{\text {con }}$. The amorphous volume $\mathrm{v}_{\mathrm{a}}$ and the amorphous surface $\mathrm{A}_{\mathrm{a}}$ are related by ${ }^{1)}$ :

$\frac{\mathrm{dv}_{\mathrm{a}}}{\mathrm{dt}}=-\frac{\mathrm{L}_{0}}{2 \mathrm{t}_{\mathrm{con}}} \mathrm{A}_{\mathrm{a}}$

[*] A. Cameirão, F. Espitalier (espitali@enstimac.fr), R. David, Laboratoire de Génie des Procédés des Solides Divisés, CNRS-Ecole des Mines d'Albi - Carmaux, F-81013 Albi Cedex 9, France; L. Rouleau, Catalysis and Separation Department, IFP-Lyon, BP 3, F-69390 Vernaison, France.

1) List of symbols at the end of the paper.
By integration of Eq. (1) one obtains the crystalline volume $\mathrm{v}_{\mathrm{c} \text { : }}$

$$
\begin{aligned}
& \text { if: } \mathrm{t}<\mathrm{t}_{0}: \quad \mathrm{v}_{\mathrm{c}}=0 \\
& \text { if } \mathrm{t}_{0} \leq \mathrm{t} \leq \mathrm{t}_{0}+\mathrm{t}_{\text {con: }} \\
& \frac{\mathrm{v}_{\mathrm{c}}}{\mathrm{v}_{0}}=1-\left[1-\frac{\left(\mathrm{t}-\mathrm{t}_{0}\right)}{\mathrm{t}_{\mathrm{con}}}\right]^{3} \\
& \text { if } \mathrm{t}>\mathrm{t}_{0}+\mathrm{t}_{\text {con }}: \quad \mathrm{v}_{\mathrm{c}}=\mathrm{v}_{0}
\end{aligned}
$$

$\mathrm{t}_{0}$ is different for each amorphous particle and is assumed to follow a Gaussian distribution with the mean value $\overline{\mathrm{t}}_{0}$ and the standard deviation $\sigma$.

$\mathrm{p}\left(\mathrm{t}_{0}\right)=\frac{1}{\sigma \sqrt{2 \pi}} \exp \left(-\frac{\left(\mathrm{t}_{0}-\overline{\mathrm{t}}_{0}\right)^{2}}{2 \sigma^{2}}\right)$

The ratio between the total crystalline volume $\mathrm{V}_{\mathrm{c}}$ and the initial amorphous volume $\mathrm{V}_{0}$ is:

$$
\frac{\mathrm{V}_{\mathrm{c}}(\mathrm{t})}{\mathrm{V}_{0}}=\int_{0}^{\mathrm{t}} \mathrm{p}\left(\mathrm{t}_{0}\right) \frac{\mathrm{v}_{\mathrm{c}}}{\mathrm{v}_{0}}\left(\mathrm{t}, \mathrm{t}_{0}\right) \mathrm{dt}_{0}
$$

The crystallinity index $\mathrm{V}_{\mathrm{c}} / \mathrm{V}_{0}$ was experimentally monitored against the time from the samples by X-ray diffraction (see Fig. 1). As an amorphous particle with an external crystalline layer can start to agglomerate, the nucleation rate of crystallites will be proportional to the surface contamination and the initial concentration of amorphous particles.

$\mathrm{r}_{\mathrm{N}}=\mathrm{N}_{\mathrm{A} 0} \mathrm{p}(\mathrm{t})$

$t_{0}$ and $t_{\text {con }}$ were calculated from the starting time $t_{\text {start }}$ of the experimental curve $\mathrm{V}_{\mathrm{c}} / \mathrm{V}_{0}$ (see Fig. 1): no amorphous 
particle begins to transform before $\overline{\mathrm{t}}_{0}-2 \sigma$; thus, for the entire suspension it is assumed that:

$\overline{\mathrm{t}}_{0}=\mathrm{t}_{\text {start }}+2 \sigma$

The half-life time $t_{50}$ of an amorphous particle is derived from Eq. (3):

$\mathrm{t}_{50}=\mathrm{t}_{0}+\frac{\mathrm{t}_{\text {conso }}}{4.85}$

For the complete set of amorphous particles, the half-life time is approximated as:

$\overline{\mathrm{t}}_{50}=\overline{\mathrm{t}}_{0}+\frac{\mathrm{t}_{\text {conso }}}{4.85}$

Then, by fitting $\sigma$ it is possible to simulate the crystallinity index $\mathrm{V}_{\mathrm{c}} / \mathrm{V}_{0}$ against the time via Eqs. (2-6), (8), and (10); $\mathrm{t}_{\text {con }}$ was found identical for all experiments and equal to $3.1 \mathrm{~h}$. Values of $\overline{\mathrm{t}}_{0}$ and $\sigma$ are reported in Tab. 1 for some typical runs. Runs 1 and 2 were done under the same chemical and stirring conditions, except a ripening period after reactant mixing, but before heating for run 2 . Run 3 was conducted under different chemical (alkalinity) and stirring conditions as runs 1 or 2 and without ripening. All the runs were done at the same temperature.

$\overline{\mathrm{t}}_{0}$ is influenced by alkalinity and ripening and by stirring speed, whilst $\sigma$ is very sensitive to ripening and alkalinity and less to the stirring speed. The crystallinity curve of the particulate mass against time (see Fig. 1) fits experimental results extremely well when using this assumption.

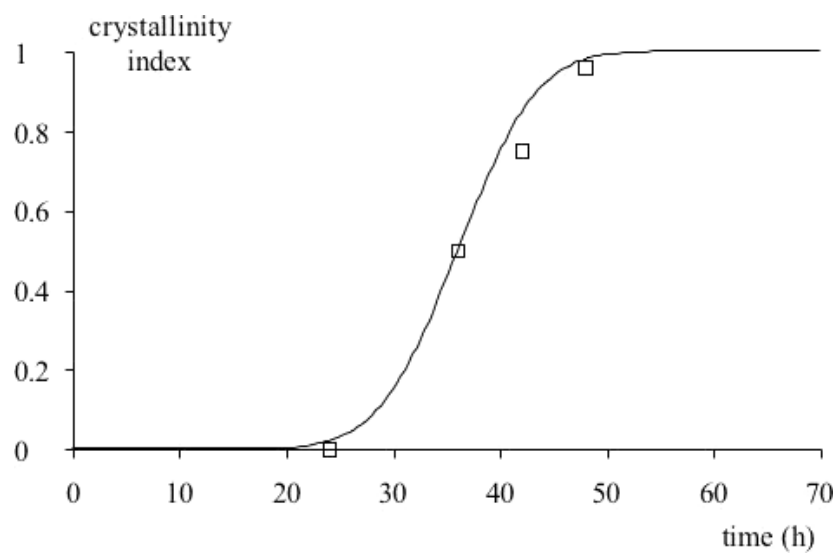

Figure 1. Cristallinity index against time for run 3.

Table 1. Values of parameters obtained for three typical runs at the same temperature (for the entire sets of experimental conditions see [1] and [2]).

\begin{tabular}{|l|c|c|c|}
\hline & Run 1 & Run 2 & Run 3 \\
\hline$\sigma[\mathrm{h}]$ & 6.5 & 8.8 & 5.7 \\
\hline$\overline{\mathrm{t}}_{0}[\mathrm{~h}]$ & 37 & 41 & 35
\end{tabular}

\section{Agglomeration Model}

A complete model [2] of the multiple agglomeration of the zeolite was set up. Crystal agglomeration starts when the particle surface is crystalline and follows a three-step process (see Fig. 2); First, collision of agglomerates or individual particles takes place and results in a labile aggregate, which may undergo either disruption or consolidation by crystal growth. It is generally accepted that the collision rate $r_{\text {col }}$ is size-dependent and linked to the concentrations of colliding species:

$\mathrm{r}_{\mathrm{col}}=\mathrm{K}_{\mathrm{col}}\left(\mathrm{S}_{\mathrm{i}}, \mathrm{S}_{\mathrm{j}}\right) \mathrm{N}_{\mathrm{i}} \mathrm{N}_{\mathrm{j}}$

where $\mathrm{K}_{\mathrm{col}}$ depends on the collision regime (Brownian if mother crystal sizes $<$ Batchelor scale, or laminar shear if Kolmogoroff scale $>$ mother crystal sizes $>$ Batchelor scale) encountered by the colliding particles:

$\mathrm{K}_{\mathrm{col}, \mathrm{B}}=2 \mathrm{kT}\left(\mathrm{S}_{\mathrm{i}}+\mathrm{S}_{\mathrm{j}}\right)^{2} /\left(3 \mu \mathrm{S}_{\mathrm{i}} \mathrm{S}_{\mathrm{j}}\right)$;

$\mathrm{K}_{\mathrm{col}, \mathrm{L}}=0.16(\mathrm{P} / \mathrm{v})^{1 / 2}\left(\mathrm{~S}_{\mathrm{i}}+\mathrm{S}_{\mathrm{j}}\right)^{3}$

Note that $\mathrm{K}_{\mathrm{col}, \mathrm{L}}$ increases with the stirring power whereas $\mathrm{K}_{\mathrm{col}, \mathrm{B}}$ is not stirring power dependent. If both particles to agglomerate are of the same size $S, K_{\text {col, } L}$ varies as $S^{3}$ and $\mathrm{K}_{\text {col, } \mathrm{B}}$ is size-independent. When keeping the largest size $\mathrm{S}_{\mathrm{i}}$ constant one can observe that $\mathrm{K}_{\mathrm{col}, \mathrm{B}}$ has a minimum for $S_{j}=S_{i}$, whereas $K_{\text {col, } L}$ reaches its maximum value for $S_{j}=S_{i}$. If the disruption of the aggregate and the crystal growth are independent processes and of first order with respect to the aggregate number concentration (i.e., not consecutive to further collisions), the agglomeration rate is the collision rate times an efficiency factor $\eta[2]$.

$\mathrm{r}_{\mathrm{aggl}}=\mathrm{r}_{\mathrm{col}} /\left(1+\mathrm{k}_{\mathrm{d}} / \mathrm{k}_{\mathrm{c}}\right)=\eta \mathrm{r}_{\mathrm{col}}$

If the crystal growth rate is high, this efficiency factor is close to 1 . By contrast, with low growth rates:

$\eta \sim \mathrm{G} /\left(\mathrm{k}_{\mathrm{d}} \mathrm{S}_{\mathrm{j}}\right)$

A reasonable assumption for $\eta_{\mathrm{B}}$ would be to consider $\mathrm{k}_{\mathrm{dB}}$ as constant. Recently, Liew et al. [3] proposed an expression for $\mathrm{k}_{\mathrm{dL}}$ :

$\mathrm{k}_{\mathrm{dL}} \sim \rho_{\mathrm{L}} \mathrm{PS}_{\mathrm{i}} /\left(\sigma^{*} \mathrm{~L}^{*}\right)$

which leads to:

$\eta_{\mathrm{L}}=\mathrm{AG} /\left(\mathrm{PS}_{\mathrm{i}} \mathrm{S}_{\mathrm{j}}\right)$

where the constant A stands for both, liquid and solid properties.

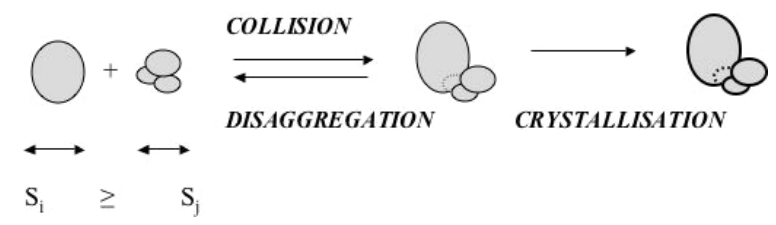

Figure 2. Processes involved in crystal agglomeration. 
Summarizing, for a given growth rate $r_{\mathrm{aggl}, \mathrm{B}}$ is not dependent on $\mathrm{P}$, it is proportional to the common size $\mathrm{S}^{-1}$, and it is minimum for agglomeration of particles of the same size. During size enlargement, agglomerations of small and large particles are thus favored (snowball effect), but the rate of agglomeration diminishes with size increase.

Conversely, $\mathrm{r}_{\mathrm{aggl}, \mathrm{L}}$ is a decreasing function of $P$ and is proportional to the common size if $S_{j}=S_{i}$. At constant $S_{i}$ it is maximum for $S_{j}=\lambda_{B}$, minimum for agglomeration of particles of $\mathrm{S}_{\mathrm{j}}=\mathrm{S}_{\mathrm{i}} / 3$, and reaches a weak secondary maximum at $S_{j}=S_{i}$. During size enlargement, if $S_{i}>>\lambda_{B}$, agglomerations of particles of very different sizes are thus favored but, if $S_{i}$ is of the same order of magnitude as $\lambda_{B}$, the rate of agglomeration becomes quasi-independent of the particle size. In several experiments size-independent agglomeration was observed [4]. Globally, the agglomeration rate is enhanced by size increase. Anyway, the agglomeration rate depends on supersaturation via $\mathrm{G}$. When the supersaturation decreases, agglomeration, which is then mainly is laminar, becomes more and more difficult. It is thus expected that agglomerates formed under Brownian and laminar shear regimes show different morphologies.

Agglomeration is modeled like a set of stoichiometric chemical reactions between particle classes [2]. The stoichiometric coefficients are designed in order to account for both mass conservation and disappearance of one particle per agglomeration.

However, the method described in [2] was improved in this paper by including a liquid volume $\mathrm{v}_{1}$ into the apparent volume of the newly formed agglomerate:

$a v_{j}+b v_{i}+v_{1} \rightarrow c v_{m}$

This allows one to predict the external porosity of the agglomerates, which was observed experimentally (see Fig. 3). The coefficients $a, b, c$, and $v_{1}$ are given in Tab. 2.

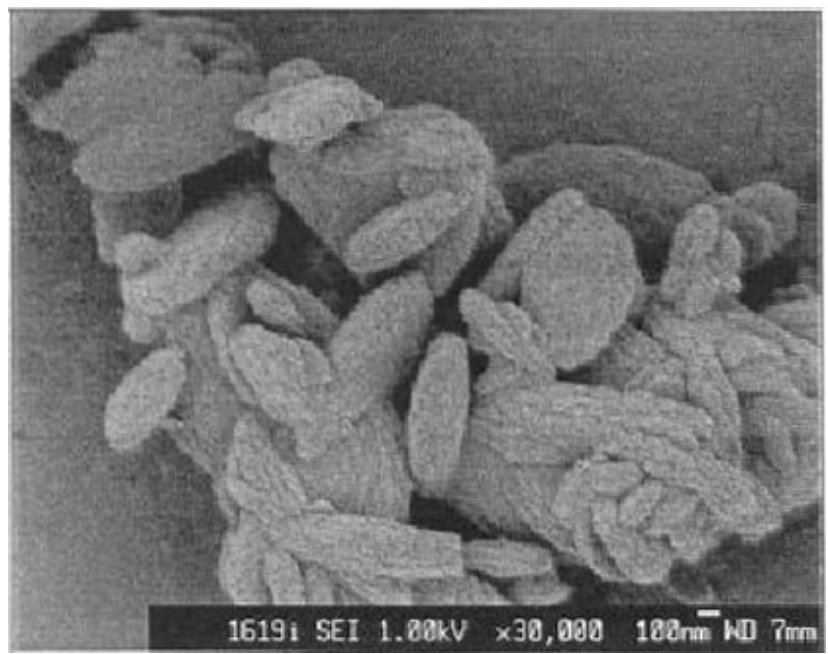

Figure 3. SEM picture of synthesized zeolite.
Then, the porosity is calculated as a function of time: It is the ratio of the mean trapped liquid volume $\bar{v}_{1}$ per unit of suspension volume to the total apparent solid volume concentration.

$\overline{\mathbf{v}}_{1}$ is calculated by integrating Eq. (18) for all interactions $(i, j)$ and their consequences for particle classes ranging from $\mathrm{n}=1$ to $\mathrm{n}_{\mathrm{c}}$ :

$$
\frac{d \bar{v}_{1}}{d t}=\sum_{n=1}^{n_{c}} \sum_{i=1}^{n_{c}} \sum_{j=1}^{i} v_{l} r_{a g g l}(i, j, n, t)
$$

All other equations of the model can be found in [2].

\section{Results and Discussion}

The calculations of the model developed above were done with the same parametric values as in [2]. The agreement obtained with the experimental agglomerate size distribution is better (see Fig. 4). Note that the laser particle sizer measures apparent external dimensions of the agglomerates including external porosity between the primary agglomerates (see Fig. 3). Two codes, both based on backward differentiation, were used: LNAG did not use a numerical Jacobian matrix, whilst LSODE does, yielding similar results. The quality of

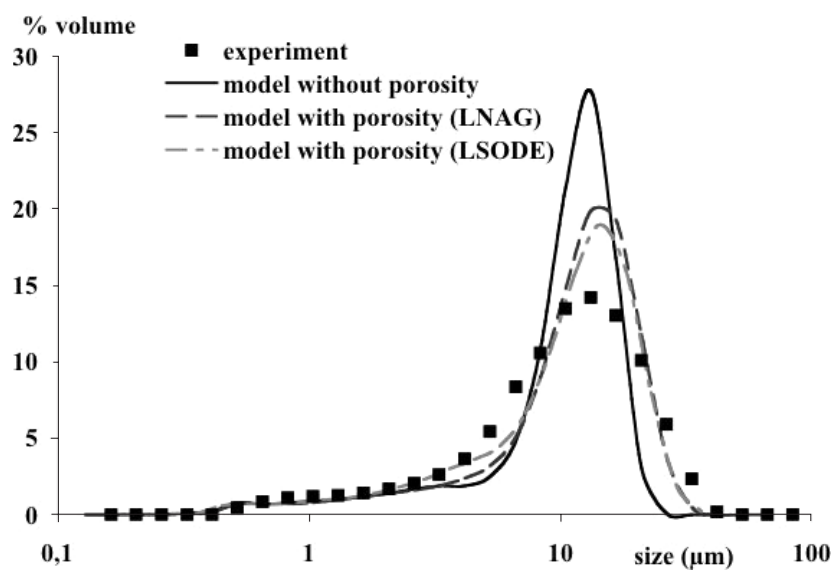

Figure 4. Apparent experimental and calculated particle size distributions with porosity modeling for run 3 using two different codes. 
the agreement is much better than the one resulting from a previous model [2], but the model does not completely fit the experimental size distribution. In fact, Tab. 2 is a very crude approach of external porosity: a finer tuning of the daughter classes of the agglomerates is necessary.

\section{Conclusions}

The agglomeration process during crystallization is far from being completely understood. The crystalline growth is a key feature of this process, which makes the major difference with colloidal aggregation by playing the role of sticking particles. In some cases like the present one, the agglomeration becomes the dominant size enlargement process, more than crystal growth. The building-up of the final particle structure from the basic crystallites is often made of several agglomeration steps. Finally, efficient models of agglomeration must consider the importance of taking external porosity, especially for secondary agglomerates, when applicable, into account.

\section{Acknowledgement}

The authors wish to thank the Institut Français du Pétrole for the financial support of this work.

Received: November 14, 2005

\section{Symbols used}

\begin{tabular}{|c|c|c|}
\hline A & {$\left[\mathrm{m}^{3} \mathrm{~s}^{-2}\right]$} & constant \\
\hline $\mathrm{A}_{\mathrm{a}}$ & {$\left[\mathrm{m}^{2}\right]$} & amorphous surface \\
\hline$a, b, c$ & {$[-]$} & stoichiometric coefficients \\
\hline $\mathrm{k}$ & {$\left[\mathrm{J}\right.$ molecule $\left.{ }^{-1} \mathrm{~K}^{-1}\right]$} & Boltzmann constant \\
\hline $\mathrm{k}_{\mathrm{c}}$ & {$\left[\mathrm{s}^{-1}\right]$} & $\begin{array}{l}\text { consolidation rate } \\
\text { constant }\end{array}$ \\
\hline $\mathrm{k}_{\mathrm{d}}$ & {$\left[\mathrm{s}^{-1}\right]$} & disruption rate constant \\
\hline $\mathrm{K}_{\mathrm{col}}$ & {$\left[\mathrm{m}^{3} \mathrm{~s}^{-1}\right]$} & collision rate constant \\
\hline $\mathrm{G}$ & {$\left[\mathrm{ms}^{-1}\right]$} & crystal growth rate \\
\hline $\mathrm{L}$ & [m] & particle size \\
\hline $\mathrm{L}^{*}$ & {$[\mathrm{~m}]$} & length of contact line \\
\hline $\mathrm{L}_{0}$ & {$[\mathrm{~m}]$} & $\begin{array}{l}\text { initial amorphous particle } \\
\text { size }\end{array}$ \\
\hline $\mathrm{N}_{\mathrm{A} 0}$ & {$\left[\mathrm{~m}^{-3}\right]$} & $\begin{array}{l}\text { initial concentration } \\
\text { of amorphous particles }\end{array}$ \\
\hline $\mathrm{N}_{\mathrm{n}}$ & {$\left[\mathrm{m}^{-3}\right]$} & $\begin{array}{l}\text { concentration of particles } \\
\text { belonging to the class } n\end{array}$ \\
\hline $\mathrm{p}\left(\mathrm{t}_{0}\right)$ & {$\left[\mathrm{s}^{-1}\right]$} & $\begin{array}{l}\text { Gaussian distribution } \\
\text { of beginning times }\end{array}$ \\
\hline $\mathrm{p}(\mathrm{t})$ & {$\left[\mathrm{s}^{-1}\right]$} & $\begin{array}{l}\text { Gaussian distribution } \\
\text { of times }\end{array}$ \\
\hline $\mathrm{P}$ & {$\left[\mathrm{W} \mathrm{kg}^{-1}\right]$} & $\begin{array}{l}\text { dissipated energy par unit } \\
\text { mass }\end{array}$ \\
\hline
\end{tabular}

$$
\begin{aligned}
& {\left[\mathrm{m}^{-3} \mathrm{~s}^{-1}\right]} \\
& {\left[\mathrm{m}^{-3} \mathrm{~s}^{-1}\right]} \\
& {\left[\mathrm{m}^{-3} \mathrm{~s}^{-1}\right]}
\end{aligned}
$$

$\begin{array}{ll}\mathrm{S}_{\mathrm{i}} & {[\mathrm{m}]} \\ \mathrm{S}_{\mathrm{j}} & {[\mathrm{m}]} \\ \mathrm{t} & {[\mathrm{s}]} \\ \mathrm{t}_{0} & {[\mathrm{~s}]}\end{array}$

$\overline{\mathrm{t}}_{0}$

$t_{\text {start }}$

$t_{\text {con }}$

$t_{50}$

$\mathrm{T}$

$\mathrm{v}_{0}$

$\mathrm{v}_{\mathrm{a}}$

$\mathrm{v}_{\mathrm{c}}$

$\mathrm{v}_{1}$

$\overline{\mathrm{v}}_{1}$

$\mathrm{v}_{\mathrm{i}}, \mathrm{v}_{\mathrm{j}}, \mathrm{v}_{\mathrm{k}}$
$\mathrm{V}_{0}$
$\mathrm{~V}_{\mathrm{c}}$
$\mathrm{V}_{\mathrm{c}} / \mathrm{V}_{0}$
$\sigma$

$\sigma^{*}$
$\lambda_{\mathrm{B}}$
$\lambda_{\mathrm{K}}$
$\rho_{\mathrm{l}}$
$\eta$
$v$
$\mu$

\section{Subscripts}

$\begin{array}{ll}\mathrm{B} & \text { Brownian } \\ \mathrm{L} & \text { laminar } \\ \mathrm{i}, \mathrm{j}, \mathrm{m}, \mathrm{n}, \mathrm{n}_{\mathrm{c}}, \mathrm{k} & \text { particle classes }\end{array}$

agglomeration rate

collision rate

nucleation rate of crystallites particle size of class $i$ particle size of class $j$ time

beginning of crystallites generation mean value of Gaussian distribution of $t_{0}$ starting time of the experimental curve conversion time of one crystallite half-life time of an amorphous particle temperature initial amorphous volume amorphous volume cristalline volume trapped liquid volume mean trapped liquid volume particle volume initial amorphous volume total crystalline volume cristallinity index standard deviation of Gaussian distribution of $t_{0}$ yield stress

Batchelor microscale Kolmogoroff microscale liquid density efficiency factor kinematic viscosity dynamic viscosity

\section{References}

[1] R. David, A. M. Paulaime, F. Espitalier, L. Rouleau, Powder Technol. 2003, 130, 338 .

[2] R. David, F. Espitalier, A. Cameirao, L. Rouleau, Kona 2003, 21, 40.

[3] T. L. Liew, J. P. Barrick, M. J. Hounslow, Chem. Eng. Technol. 2003, 26, 282. DOI: $10.1002 /$ ceat.200390042

[4] J. P. Andreassen, M. J. Hounslow, AIChE J. 2004, 50, 2772. 